\title{
ECONOMIA E DESENVOLVIMENTO SOCIAL: A POSSIBILIDADE DA UTILIZAÇÃO DE INDICADORES SOCIAIS PARA AVALIAÇÃO DO DESENVOLVIMENTO PARANAENSE
}

\author{
Daniel Vitor Vicente ${ }^{1}$
}

\begin{abstract}
RESUMO
Este trabalho pretende analisar a progressão de indicadores sociais no Paraná a partir dos anos 1990, utilizando como base de dados os indicadores sociais de Educação, Emprego e Renda, Saúde e Saneamento, disponibilizados pelo Instituto Paranaense de Desenvolvimento Econômico e Social - IPARDES. Para o desdobramento de tal reflexão, será resgatado brevemente o desenvolvimento econômico Brasileiro, cujo projeto de Estado está embasado no que se conhece por novo desenvolvimentismo. Do mesmo modo, também será abordada a possibilidade de serem utilizados indicadores sociais públicos e gratuitos, a fim de que os mesmos auxiliem nos procedimentos de análise e problematização de questões sociais que interessam às Ciências Sociais, utilizando-se como exemplo os dados que serão apresentados.
\end{abstract}

Palavras-chave: Indicador. Paraná. Ipardes. Novo desenvolvimentismo.

\footnotetext{
${ }^{1}$ Mestrando do Programa de Pós-Graduação em Ciências Sociais da Universidade Estadual de Londrina, Brasil.daniel.vitore@gmail.com
} 


\title{
ECONOMY AND SOCIAL DEVELOPMENT: THE POSSIBILITY OF USING SOCIAL INDICATORS TO EVALUATE THE DEVELOPMENT OF THE STATE OF PARANÁ
}

\begin{abstract}
This paper aims to analyze the progression of social indicators in Paraná from the 1990s, using the social indicators of Education, Employment and Income, Health and Sanitation as database, which were provided by the Economic and Social Development Institute of Paraná (Instituto Paranaense de Desenvolvimento Econômico e Social - IPARDES). To reflect on that, we will briefly present the Brazilian economic development, having the State project based on the so called new developmentalism. Similarly, we will also address the possibility of using public and free social indicators, so that they can help during the analysis and questioning of the social issues which concern Social Sciences, using the data that will be presented as an example.
\end{abstract}

Keywords: Indicators. Paraná. IPARDES. New developmentalism.

\section{INTRODUÇÃO}

omo retratar a face humana do desenvolvimento? A questão proposta em todas as edições da revista Desafios do Desenvolvimento, publicada pelo IPEA - Instituto de Pesquisas Econômicas e Aplicadas, busca caracterizar os desafios e mudanças históricas das condições de existência da nação brasileira nos séculos em que o país se desenvolveu política, econômica e socialmente. Utilizar as informações dos indicadores como um instrumento operacional para monitorar aspectos da realidade social garante a possibilidade de intervenção através das políticas públicas e, ao se utilizarem as informações fornecidas pelos indicadores sociais, é possível monitorar aspectos do social, a fim de que seja possível intervir de maneira que a sua transformação seja significativa.

0 presente trabalho está divido em duas seções. Na primeira, será delineado um breve histórico da economia e do desenvolvimento brasileiro e paranaense, buscando elucidar as especificidades e desdobramentos na sociedade brasileira e também as regionais. Na segunda seção, busca-se apresentar a realidade das possibilidades de pesquisa através dos indicadores sociais gratuitos disponibilizados por entidades governamentais. Os indicadores são utilizados, neste caso, como um recurso metodológico e empírico que traz alguma informação sobre a realidade, sobre algum aspecto de mudanças que ocorrem nas sociedades, ou em recortes específicos (que vão desde um bairro até um continente). Com o intuito de demonstrar a possibilidade de 
utilização destes dados, será apresentada uma síntese de resultados de indicadores do Estado do Paraná.

\section{BREVE HISTÓRICO DA ECONOMIA BRASILEIRA}

No decorrer do século XX, o Brasil passou por uma revolução que transformou radicalmente seu modelo econômico e suas estruturas sociais, modos de sociabilidade, comunicações e política. No início do século XX, abalado por resquícios das mudanças estruturais do final do século anterior - como a abolição da escravatura, fim do tráfico negreiro, início do assalariamento e a outorga da Constituição da República -, o país encontrava-se em crises de produção, principalmente relacionados coma crise mundial de 1929 e a crise cafeeira de 1930 (PAIVA, 2008, p. 411).

0 início dos anos 1930 foi favorável ao país, ainda que estivesse afetado pelas restrições de importações, tendo o Estado como centralizador das decisões econômicas. Historicamente conhecido como Estado Novo, este "representou uma aliança da burocracia civil e militar e da burguesia industrial, cujo objetivo comum imediato era 0 de promover a industrialização do país sem grandes abalos sociais." (FAUSTO, 2012, p. 201). No que concerne ao cenário de desenvolvimento regional - sobretudo em relação ao Paraná -, apresenta-se, a partir desta mesma época, o início de um processo de desenvolvimento que buscava se equiparar ao da Região Sudeste (especialmente São Paulo), mas com dinâmicas específicas do estado, a exemplo da expansão cafeeira (TRINTIN, 2005, p. 3).

Com o fim do Estado Novo, inicia-se em 1945 uma experiência democrática no país. Em termos de economia, o intervalo de 1945-1964 foi de crescimento econômico considerável (BONELLI, 2005, p. 311). Inicialmente a política do governo Dutra mostrou-se liberal. Porém foi a centralização do Estado que liderou o processo de desenvolvimento. No decorrer do pós-guerra, o país começou a negociar investimentos e financiamentos externos:

A criação da Comissão Mista Brasil - Estados Unidos em 1951, as negociações com o Banco Mundial e o Exmibank americano foram passos importantes. Em 1952 foi criado o BNDE para organizar a contrapartida nacional dos recursos externos (DELFIM NETTO, 2005, p. 234).

Contudo, cabe ressaltar que a dinâmica de importações era selecionada visando 0 desenvolvimento industrial e com protecionismo da taxa de câmbio. No cenário paranaense, o estado já havia se consolidado como o maior produtor de café de todo 0 país. A consolidação da produção cafeeira garantiu a expansão econômica e também da infraestrutura do estado: rodovias (para escoamento da produção), expansão urbana 
(aumento populacional), e fluxos migratórios nas diversas regiões de plantio (TRINTIN, 2001, p. 77).

0 período que compreende os anos de 1951 a 1954 (segundo governo de Getúlio Vargas) foram conturbados econômica e socialmente, com a eclosão de greves dos trabalhadores urbanos, crises nas relações internacionais, atentados e abandono do apoio militar. Neste ínterim, o suicídio de Vargas trouxe nova instabilidade política e econômica, perdurando até a eleição de Juscelino Kubitschek (BONELLI, 2005, p. 313).

0 governo JK (entre 1956 e 1961) ficou conhecido por conceber mudanças estruturais na economia brasileira, planejamento econômico e projeções de crescimento. 0 Plano de Metas foi uma política econômica que resultou no crescimento do país.

Ele abrangia 31 objetivos, distribuídos em seis grandes grupos: energia, transportes, alimentação, indústrias de base, educação e a construção de Brasília, chamada de metassíntese. (FAUSTO, 2012, p. 235).

0 crescimento econômico neste período foi notável, chegando o PIB à taxa anual de 7\%. Houve também o incentivo da industrialização automobilística no país, que se concentrou na região do ABC paulista (FAUSTO, 2012, p. 236).

Frente à desaceleração do crescimento no início dos anos 1960 e a escalada da inflação, foi criado, em 1963, o Plano Trienal, elaborado por Celso Furtado, que buscava restabelecer o crescimento econômico, as reformas sociais e a inflação. Entretanto 0 plano não foi apoiado pelos setores que detinham o poder econômico, estes estavam contra o governo de João Goulart, o que acabou por restringir o investimento externo. Por conseguinte, as instabilidades políticas, manifestações da esquerda e direita e a falta de controle nas decisões abriram espaço para a derrubada do poder constituído pelo militarismo (BONELLI, 2005, p. 314). No Paraná houve também certa estagnação, crise da produção cafeeira e de reservas florestais. 0 setor produtivo também ficou estagnado, sendo este dependente da produção de café e processamento primário de matérias primas (TRINTIN, 2001, p. 79).

Quanto à economia brasileira, o período que transcorre o poder militar pode ser dividido em três fases: Reforma, crescimento e equilíbrio (1964-1973); Choque, crescimento e crise (1974-1979) e Ajuste estrutural, crescimento e inflação (1980-1985) (DELFIM NETTO, 2005, p. 234).

A primeira fase (1964-1973) foi conhecida por restabelecer padrões de crescimento econômico, equilíbrio externo, reformas no setor público, reformas trabalhistas, organização nas taxas de câmbio, melhora na organização e gestão das empresas públicas. 0 conjunto destas ações era parte da proposta do PAEG (Programa de Ação Econômica do Governo). As ações que mais afetaram a população foram: 0 
aumento de impostos, elevação dos preços de produtos básicos, compressão de salários; medidas legislativas dificultaram o direito à greve e também foi extinta a estabilidade empregatícia após dez anos de trabalho, que era até então garantida pela CLT Consolidação das Leis de Trabalho. Para compensar tal efeito, foi criado o FGTS Fundo de Garantia do Tempo de Serviço (FAUSTO, 2012, p. 260).

Na segunda fase (1974-1979) o Brasil foi mais afetado por agentes externos, tendo como principal fator a crise internacional do petróleo, de 1973 (neste período 0 Brasil importava mais de $80 \%$ do total de petróleo consumido). Para conter tal crise, foi lançado o II Plano Nacional de Desenvolvimento. Este plano baseou-se no desenvolvimento da produção autônoma de insumos básicos (aço, petróleo, alumínio), energia elétrica e a substituição parcial da gasolina pelo álcool. No Paraná o resultado do II PND resultou numa diversificação da indústria, início da substituição da simples produção e exportação agrícola pela produção e industrialização dos produtos agrícolas (OLIVEIRA, 1994, p. 11). 0 Plano tentou manter a estabilidade, mas teve que ceder à segunda crise internacional do petróleo, ocorrida em 1979 (BONELLI, 2005, p. 316).

A terceira fase (1980-1985) foi marcada por restrições frente à crise internacional: houve queda de investimentos e corte nas despesas públicas. A crise internacional aumentou os juros em geral, e os países industrializados também obtiveram baixo crescimento. No Brasil e no Paraná o cenário é semelhante, com queda nas taxas do PIB a partir de 1981 até 1984 . 0 crescimento econômico no país voltou a ser contínuo, mas era necessário abater as dívidas externas. Apesar do sucessivo aumento na inflação, a partir de 1984 a economia voltou a se restabelecer, apresentando um crescimento contínuo que perdurou até o fim da década (DELFIM NETTO, 2005, p. 243244; TRINTIN, 2005, p. 9).

A partir de 1985, apesar das mudanças e fatalidades políticas, como a morte de Tancredo Neves, houve um ligeiro crescimento no produto agregado (bens e serviços), bem como aumento no consumo e nas exportações e sucessiva queda nas importações. Em 1986, o lançamento do Plano Cruzado em fevereiro de 1986, ordenado pelo então presidente José Sarney, intentava conter a inflação e congelar os preços, além do reajuste do salário mínimo e aumento do mesmo paralelamente ao aumento da inflação (FAUSTO, 2012, p. 287). Todo o período entre 1986 e 1992 foi representado por instabilidade, reajuste de preços, aumento constante da inflação. Vários planos econômicos (Cruzado II, Bresser, Verão, Collor) buscaram conter as crises, regular as taxas de câmbio, estabilizar a inflação crescente. Houve também contínuo aumento do PIB aplicado aos setores públicos, inviabilizando o investimento deste nos setores econômicos que mais necessitavam, muito menos em reformas sociais (DELFIM NETTO, 2005, p. 246). 
Implantado em 1994, o Plano Real foi o responsável por garantir um retorno ao crescimento econômico, estabilização de preços, queda da inflação e aumento do salário real. Finalmente, a partir de 1996, projetava-se um crescimento contínuo no PIB, ainda que ameaçado pela crise asiática que ocorrera anos mais tarde, entre 1997 e 1998.

As mudanças sociopolíticas do início do século XXI e a crise internacional frearam o crescimento projetado e também impediram o desenvolvimento brasileiro no início do novo século (BONELLI, 2005, p. 318).

A discussão sobre o novo desenvolvimentismo inicia-se a partir do início do século XXI, em especial nos países da América Latina. Após duas décadas de crises, privatizações, dívidas externas, liberalização econômica, mudanças e estratégias visando a estabilidade macroeconômica, grupos de pesquisadores verificaram a que desenvolvimento econômico não estava em plena consonância com o desenvolvimento social. 0 pensamento novo desenvolvimentista busca conciliar 0 desenvolvimento econômico e social (MATTEI, 2011, p. 2).

Bresser Pereira (2006), em linhas gerais, simplifica a corrente de pensamento que tem buscado orientar os planejamentos de políticas econômicas e sociais a partir do início do século XXI no Brasil.

É um conjunto de propostas de reformas institucionais e de políticas econômicas, por meio das quais as nações de desenvolvimento médio buscam, no início do século XXI, alcançar os países desenvolvidos. (PEREIRA, 2006, p. 12).

De acordo com o autor, são inúmeros os fatores que garantem o desenvolvimento na atualidade brasileira:

0 aumento da capacidade de poupança e investimento da nação, a forma pela qual incorpora progresso técnico na produção, o desenvolvimento do capital humano, o aumento da coesão social nacional que resulta em capital social ou em sociedade civil mais forte e democrática, uma política macroeconômica que garanta a saúde financeira do Estado e do EstadoNação, levando a índices de endividamento interno e externo dentro de limites conservadores, são elementos constitutivos de uma estratégia nacional de desenvolvimento (PEREIRA, 2006, p. 13-14).

Delfim Netto (2005) já apontava como poderia ser o desenvolvimento econômico nacional sólido: este deve ser coordenado pelo Estado, garantindo a estabilidade monetária e aprimorando os serviços essenciais à população: saúde, justiça, educação, saúde e saneamento (DELFIM NETTO, 2005, p. 254). 
Em síntese, houve nas últimas décadas uma evolução favorável da economia brasileira, resultando, com o auxílio de políticas sociais e programas recentes do Governo Federal, visando controlar os gastos públicos, a inflação e, sobretudo, melhoras nas condições materiais nos aspectos sociais da população brasileira. Porém, a forma como estas políticas são concretizadas e o ritmo com que estas políticas afetam diretamente as condições socioeconômicas da população brasileira ainda são esparsas e demoradas, fazendo com que a redução da desigualdade social, ainda que esteja se materializando aos poucos, não consiga de forma eficiente desfazer um histórico de concentração de renda presente há séculos no país. Por isso, ainda que seja valorizado e extremamente difundido o discurso do pleno desenvolvimento social nos últimos anos, e que estes se mostrem positivos, é válido, por conseguinte, avaliar de que forma e em quais setores estas novas políticas propiciaram tais melhoras.

\section{INDICADORES SOCIAIS E USO DE INFORMÁTICA}

De acordo com Dwyer (2010), a partir do advento da informática e das tecnologias de informação e comunicação, somos capazes de produzir mudanças nos procedimentos de coleta e análise de dados científicos que podem ser utilizados em pesquisas científicas, com maior rigor e controle de dados. Pode-se, através destas ferramentas, acompanhar fenômenos sociais, identificar e indicar possíveis soluções para problemas sociais (DWYER, 2010, p. 175). 0 autor considera que:

É possível prever a emergência de sociólogos com novas qualificações, formados em Ciências Sociais e no uso das TIC (Tecnologias de Informação e Comunicação); eles terão a capacidade de produzir conhecimentos mais robustos e ideias avaliadas como mais capazes de dar conta das complexidades de nosso mundo em transformação (DWYER, 2010, p. 175).

As pesquisas sociais são fundamentais, portanto, para elevar o grau de compreensão das questões e problemas de um determinado campo de pesquisa. De acordo com Levin e Fox (2004, p. 2), "A pesquisa social pode tomar muitas formas e ser usada para investigar uma ampla gama de problemas."

De acordo com Baltar e Baltar (2010), a produção científica em ciências sociais é escassa quando nos referimos à utilização de ferramentas de informática como suporte à pesquisa social, a exemplo do software SPSS ${ }^{2}$, que desde 1995 até 0 ano de 2010, possui apenas um artigo de ciências sociais indexado ao Scielo, que contenha a utilização de tal programa como ferramenta de análise na pesquisa (BALTAR; BALTAR, 2010, p. 14).

Através do acesso a dados estatísticos (usualmente concedidos por instituições governamentais e gratuitas), pode-se auxiliar a elaborar uma utilidade pública da 
Sociologia, "em que, por meio de suas análises, ela possa ajudar cidadãos a verificar a validade de velhas compreensões e construir novas compreensões do mundo ao redor" (DWYER, 2010, p. 165).

É esta proposta que a presente seção tende a apresentar. Entidades governamentais, em destaque o Instituto Brasileiro de Geografia e Estatística - IBGE, o Instituto de Pesquisa Econômica Aplicada - IPEA, e o Instituto Paranaense de Desenvolvimento Econômico e Social - IPARDES dispõem de ferramentas públicas de acesso a informações, dados estatísticos, pesquisas e indicadores sociais que podem ser acessados via internet. Através destes instrumentos, podemos verificar inúmeros indicadores relacionados a temas variados da estrutura social brasileira. Dados demográficos, econômicos, sociais, culturais relativos a todos os setores sociais e em épocas e períodos variados.

Neste artigo foi definida a opção da utilização de indicadores sociais relativos ao Estado do Paraná. Buscando verificar as teses e propostas do planejamento novo desenvolvimentista, que enfatiza a equidade, a justiça social e o acesso a políticas públicas de direito, decidiu-se apresentar os indicadores relativos à educação, ao emprego, à saúde e ao saneamento. Através do site (para este artigo, os dados disponíveis foram coletados exclusivamente do Instituto Paranaense de Desenvolvimento Econômico e Social - IPARDES), são escolhidas as variáveis desejadas e os intervalos de tempo disponíveis relativos ao indicador escolhido. Como será mais bem demonstrada a seguir, a dimensão temporal das tabelas é variada devido à disponibilidade dos dados. No entanto, buscou-se concentrá-las a partir dos anos 1990 até o último Censo, realizado pelo IBGE em 2010.

\section{EDUCAÇÃO}

0 indicador inicial para a educação apresentado é o Índice de Desenvolvimento da Educação Básica - IDEB, instituído em 2007, através do Decreto nº 6.094, de 24 de abril de 2007. Este é o primeiro indicador criado para avaliar a qualidade do ensino em cada escola no Brasil. Para a formulação deste indicador, sua metodologia é realizada:

[...] a partir dos dados sobre rendimento escolar, combinados com 0 desempenho dos alunos, constantes do censo escolar e do sistema de avaliação da educação básica - SAEB, composto pela avaliação nacional da educação básica - ANEB e a avaliação nacional do rendimento escolar (prova Brasil) (BRASIL, 2007). 
A avaliação, que abrange as escolas municipais e estaduais de todo o país, garante uma avaliação de transparência pública quanto à qualidade dos estabelecimentos escolares.

0 IDEB é um indicador cuja avaliação das escolas varia em um índice de 0 a 10. 0 MEC - Ministério da Educação e Cultura estipulou como meta para 0 ano de 2022 um índice nacional de 6,0. Para garantir tal feito, fica previsto em lei (decreto acima), o apoio institucional e financeiro às escolas que a cada dois anos não são capazes de acompanhar a projeção nacional estipulada. Vejamos os dados referentes ao Paraná.

Tabela 1 - Índice de Desenvolvimento da Educação Básica (IDEB) do Estado do Paraná nos anos de 2007, 2009 e 2011.

\begin{tabular}{ccc}
\hline Ano & IDEB Estadual & Meta Nacional \\
\hline 2007 & 4,8 & 4,8 \\
2009 & 5,3 & 4,8 \\
2011 & 5,4 & 5,2 \\
\hline
\end{tabular}

Fonte: IPARDES (2012).

Como é apontado, o IDEB geral do Estado do Paraná apresenta um índice modestamente superior ao índice nacional, mas aponta uma projeção positiva quanto à meta estabelecida pelo Ministério da Educação.

0 fenômeno do analfabetismo no país é uma realidade histórica que remonta aos séculos de colonização e escravidão. Em meados de 1880, apenas 1,8\% da população brasileira era considerada alfabetizada (BRASIL, 2003). No entanto, desde as primeiras décadas do século XX o Estado Brasileiro reuniu esforços na tentativa de erradicar o analfabetismo no país. Destacam-se como políticas educacionais:

Campanha de Educação de Adolescentes e Adultos (1947, Governo Eurico Gaspar Dutra); Campanha Nacional de Erradicação do Analfabetismo (1958, Governo Juscelino Kubitschek); Movimento de Educação de Base (1961, criado pela Conferência Nacional de Bispos do Brasil-CNBB); Programa Nacional de Alfabetização, valendo-se do método Paulo Freire (1964, Governo João Goulart); [...] Declaração Mundial de Educação para Todos (assinada, em 1993, pelo Brasil em Jomtien, Tailândia); Plano Decenal de Educação para Todos (1993, Governo Itamar Franco) [...] (BRASIL, 2003, p. 12). 
A partir de tal constatação, nota-se que a problemática do analfabetismo não se restringe somente à dificuldade do acesso à educação das gerações em décadas anteriores, mas compreende também uma forma de insuficiência das políticas educacionais de atingirem toda a população, e garantir que, a partir de tais políticas, melhores resultados sejam apresentados (SOUZA, 1999, p. 17). No entanto, a última década pôde apresentar uma melhoria em relação às taxas de analfabetismo. Segue, abaixo, o indicador no Paraná:

Tabela 2 - Taxa (\%) de analfabetismo do Estado do Paraná por idade (em anos)

\begin{tabular}{cccccccc}
\hline Ano & $\begin{array}{c}\leq 15 \\
\text { anos }\end{array}$ & $\begin{array}{c}15-19 \\
\text { anos }\end{array}$ & $\begin{array}{c}20-24 \\
\text { anos }\end{array}$ & $\begin{array}{c}25-29 \\
\text { anos }\end{array}$ & $\begin{array}{c}30-39 \\
\text { anos }\end{array}$ & $\begin{array}{c}40-49 \\
\text { anos }\end{array}$ & $\begin{array}{c}\geq 50 \\
\text { anos }\end{array}$ \\
\hline 1991 & 14,85 & 4,21 & 5,57 & 7,13 & 10,95 & 19,79 & 35,59 \\
1996 & 11,12 & 2,14 & 2,64 & 3,59 & 5,76 & 12,3 & 31,81 \\
2000 & 9,53 & 1,62 & 2,42 & 3,39 & 5,38 & 9,83 & 25,34 \\
2010 & 6,28 & 0,88 & 1 & 1,42 & 2,65 & 5,16 & 15,89
\end{tabular}

Fonte: IPARDES (2012).

Relativamente às taxas de analfabetismo, o Paraná apresentou uma média de $4,75 \%$, comparado à taxa de $9 \%$ de analfabetos em todo o Brasil, segundo o Censo de 2010, realizado pelo IBGE. É presenciada em todas as faixas etárias uma melhoria na educação paranaense com a progressão dos anos. Destaque às faixas etárias relacionadas ao fim da idade escolar básica (ensino médio), na qual a taxa de analfabetismo é de apenas $0,88 \%$. Nota-se também, através do aumento nas matrículas de Ensino de Jovens e Adultos, a redução no analfabetismo da população com idade adulta. 
Tabela 3 - Número de matrículas nas modalidades de Ensino no Estado do Paraná2.

\begin{tabular}{cccc}
\hline Ano & Ensino Regular & Educação de Jovens e Adultos (EJA) & Educação Superior \\
\hline 1991 & & & 99.422 \\
2000 & & 195.635 & 186.113 \\
2007 & 2.485 .227 & 185.198 & 316.496 \\
2008 & 2.508 .002 & 161.462 & 329.741 \\
2009 & 2.514 .947 & 165.705 & 324.937 \\
2010 & 2.495 .161 & 143.586 & 335.303 \\
2011 & 2.457 .014 & & 348.077 \\
\hline
\end{tabular}

Fonte: IPARDES/ (2012)

Em relação ao número de matrículas, podemos notar alguns indicadores interessantes. A breve redução no número de matrículas no Ensino Regular (creche, préescola, fundamental, médio ou profissional) pode ser possivelmente explicada pela diminuição da natalidade no Estado, que passou de mais de 200 mil no ano de 1994 para 179.373 nascimentos em 2000, chegando até o índice de 152.049 nascimentos no ano de 2010 (INSTITUTO PARANAENSE DE DESENVOLVIMENTO ECONÔMICO E SOCIAL, 2012). 0 número de matrículas do EJA se mantém estável, registrando uma média de 153.123 matrículas. A maior expansão quanto ao número de matrículas é presenciado no Ensino Superior, que teve um aumento de 250\% nos períodos analisados, passando de 99.422 matrículas em 1991 para 186.113 em 2000, e finalmente registrando um índice de 348.077 matrículas no ano de 2010.

Os últimos indicadores apresentados são referentes à reprovação, abandono e distorção idade-série na educação básica. Segue abaixo a tabela:

${ }^{2}$ As células em branco na tabela são correspondentes a um dado não disponível. 
Tabela 4 - Taxas (\%) de Reprovação, Abandono e Distorção Idade-Série ${ }^{3}$ no Estado do Paraná nos anos 2006-2010

\begin{tabular}{ccccccc}
\hline Ano & $\begin{array}{c}\text { Reprovação - } \\
\text { Ensino } \\
\text { Fundamental }\end{array}$ & $\begin{array}{c}\text { Reprovação } \\
\text { - Ensino } \\
\text { Médio }\end{array}$ & $\begin{array}{c}\text { Abandono - } \\
\text { Ensino } \\
\text { Fundamental }\end{array}$ & $\begin{array}{c}\text { Abandono } \\
\text { - Ensino } \\
\text { Médio }\end{array}$ & $\begin{array}{c}\text { Distorção Idade- } \\
\text { Sére- Ensino } \\
\text { Fundamental }\end{array}$ & $\begin{array}{c}\text { Distorção } \\
\text { Idade-Série - } \\
\text { Ensino Médio }\end{array}$ \\
\hline 2006 & 13,7 & 12,8 & 3,2 & 13,5 & 16,9 & 30 \\
2007 & 10,3 & 11,3 & 2 & 9 & 16,4 & 28,6 \\
2008 & 9,9 & 11,5 & 2,4 & 10,3 & 15,6 & 26,9 \\
2009 & 8,8 & 11,1 & 2,1 & 8,3 & 15,4 & 25,5 \\
2010 & 9,2 & 11,7 & 2 & 6,7 & 14,8 & 23,9 \\
\hline
\end{tabular}

Fonte: IPARDES (2012).

Infelizmente, as referidas taxas não apresentam uma progressão positiva tão acentuada: redução de 4,5\% sobre a reprovação no ensino fundamental e apenas 1,1\% no ensino médio (médias de 10,38 e 11,68, respectivamente); redução de 1,1\% nas taxas de abandono do ensino fundamental (ponto positivo neste indicador: 0 abandono está próximo a zero), e redução de 6,8\% no abandono do ensino médio (com médias de 2,34 e 9,56, respectivamente); redução de $2,1 \%$ na taxa de distorção idade-série de ensino fundamental e 6,1\% para a mesma taxa referente ao ensino médio (com médias de $15,82 \%$ e $26,98 \%$, respectivamente). Como se nota, as taxas de distorção idade-série são as mais elevadas.

\section{EMPREGO E RENDA}

A análise sobre emprego a ser apresentada tende a descrever de forma breve uma relação entre a dinamização da produtividade e do mercado de trabalho. De acordo com Delgado e Besen (2009) a economia Paranaense apresentou uma dinâmica de oscilações entre os anos 2002 e 2007 (DELGADO; BESEN, 2009, p. 2). Considerando o período apresentado, a produção industrial apresentou crescimento médio entre 2001 e 2007. Ainda de acordo com os autores:

Adicionalmente à expansão da atividade econômica é importante ressaltar os efeitos positivos sobre as rendas pessoais (do trabalho e da previdência

\footnotetext{
${ }^{3}$ A taxa de distorção idade-série corresponde a proporção de alunos, em cada série do ensino fundamental e médio, com idade superior à idade recomendada para frequentar a modalidade de ensino. A idade recomendada para o ensino fundamental é de no máximo 14 anos (anos iniciais de 6 a 10 anos e anos finais de 11 a 14 anos de idade), e a idade recomendada para o ensino médio é de 15 a 17 anos de idade (Secretaria de Estado da Educação - SEED).
} 
social) decorrentes de políticas de valorização do salário mínimo e de transferências de renda; no caso paranaense, a política de valorização do salário foi reforçada com a instituição, a partir de 2006, do piso regional. (DELGAD0; BESEN, 2009, p. 4)

0 indicador que pode apontar o poder aquisitivo familiar é a renda média domiciliar. De acordo com o Instituto de Pesquisa Econômica Aplicada - IPEA (2012):

Para captar o poder aquisitivo da população, utilizamos o indicador da renda domiciliar per capita, pois ele contempla todas as fontes de renda que uma família pode possuir, dividido pela quantidade de componentes da família. Expressa, portanto, a parcela da renda que é efetivamente apropriada por cada membro da família para seus gastos (INSTITUTO DE PESQUISA ECONÔMICA APLICADA, 2012, p. 14).

0 rendimento médio das famílias paranaenses apresentou considerável desenvolvimento, superando as médias Nacionais e da Região Sul do país. De acordo com o IPEA, o Paraná passou de um rendimento médio familiar de R \$553,04 em 2001 para $\mathrm{R} \$$ 735,33 em 2009, chegando a $\mathrm{R} \$$ 870,59 em 2010 (INSTITUTO DE PESQUISA ECONÔMICA APLICADA, 2012, p. 12).

Outro indicador que pode ser utilizado para representar aspectos do desenvolvimento econômico e social é o PIB per capita. 0 PIB per capita compreende a razão entre o PIB [segundo definição do IBGE: total de riqueza (bens e serviços) gerada por um período de tempo (geralmente de um ano) em um espaço geográfico (país, região, estado ou município) global dividido pelo número absoluto de habitantes]. Teoricamente, quanto maior o PIB per capita, mais desenvolvido é o país e mais os habitantes se beneficiam dos bens e serviços produzidos no país. Porém, este indicador apresenta uma limitação: "A situação média representada pelo indicador pode estar condicionada por forte concentração de riqueza no estrato superior de renda, não deixando transparecer a existência de situações de pobreza extrema" (REDE INTERAGENCIAL DE INFORMAÇÃO PARA A SAÚDE - RIPSA, 2008, p. 96). A avaliação do PIB per capita pode ser positiva caso a população estudada não possua altos índices de pobreza extrema. No caso do Paraná, a taxa de pobreza extrema está calculada em apenas 2,3\% da população (INSTITUTO DE PESQUISA ECONÔMICA APLICADA, 2012, p. 16). No caso específico é apresentado o PIB per capita do Estado do Paraná, comparado ao do Brasil. 
Tabela 5 - Produto Interno Bruto per Capita $(\mathrm{R} \$ 1,00)$ do Paraná e do Brasil nos anos 2002-2010.

\begin{tabular}{lcc}
\hline Ano & Paraná & Brasil \\
\hline 2002 & 9.023 & 8.378 \\
2003 & 11.049 & 9.498 \\
2004 & 12.080 & 10.692 \\
2005 & 12.344 & 11.658 \\
2006 & 13.152 & 12.687 \\
2007 & 15.711 & 14.465 \\
2008 & 16.927 & 15.992 \\
2009 & 17.779 & 16.918 \\
2010 & 20.814 & 19.766 \\
\hline
\end{tabular}

Fonte: IPARDES (2012).

Os dados apresentam uma taxa considerável de crescimento do PIB, que se manteve sempre acima do PIB per capita nacional. 0 crescimento contínuo também indica que os aspectos do desenvolvimento econômico, somado à baixa taxa de pobreza do estado, revelam que o Paraná garante uma melhoria continua nas condições socioeconômicas da população.

No intuito de validar a ferramenta de pesquisa digital disponibilizada pelo IPARDES, segue uma tabela demonstrando a dinâmica do emprego formal (empregos declarados no CAGED - do ministério do trabalho) no Estado do Paraná, no intervalo de 1996-2010.

Tabela 6 - Indicadores de Emprego Formal - Paraná - 1996 -2010

\begin{tabular}{cccc}
\hline Ano & Emprego Formal - Admitidos & Emprego Formal - Desligados & Emprego Formal - Saldo \\
\hline 1996 & 628.416 & 637.347 & -8.931 \\
2000 & 710.085 & 643.846 & 66.239 \\
2010 & 1.403 .546 & 1.261 .064 & 142.482 \\
\hline
\end{tabular}

Fonte: IPARDES (2012).

Como é notado, pode-se acompanhar nos intervalos um expressivo aumento no quadro de empregos formais no Estado. Ainda que a taxa de desligados 
(dispensa/demissões) se mantenha alta, nos últimos anos esta apresenta seu saldo como indicador positivo e crescente. De acordo com Moraes Neto:

Esse bom desempenho do mercado de trabalho no Paraná nos dois últimos anos é reflexo do dinamismo da base produtiva do Estado, sobretudo de seu agronegócio, que encontrou uma situação bastante favorável do mercado internacional, principalmente para commodities agrícolas. Contou, também - a despeito dos constrangimentos de política econômica prevalecentes no cenário nacional e das limitações por parte dos estados federados em implementarem políticas econômicas regionais -, com um conjunto de estímulos à economia paranaense, desde o início do atual governo, voltados particularmente para as micro e pequenas empresas, grandes geradoras de emprego (2005, p. 5).

0 último indicador relacionado ao emprego e renda diz respeito à remuneração média dos empregos formais no Estado. A divisão entre os salários está de acordo com a metodologia do IBGE.

Tabela 7 - Remuneração Média em Salários mínimos no Paraná nos anos 1999-2010

$$
(\mathrm{sm}=\text { Salário Mínimo })
$$

\begin{tabular}{|c|c|c|c|c|c|c|c|c|c|c|c|c|c|}
\hline Ano & $\begin{array}{c}\leq 0,5 \\
\text { sm }\end{array}$ & $\begin{array}{c}0,51- \\
1,00 \\
\mathrm{sm}\end{array}$ & $\begin{array}{c}1,01- \\
1,50 \\
\mathrm{sm}\end{array}$ & $\begin{array}{c}1,51- \\
2,00 \\
\mathrm{sm} \\
\end{array}$ & $\begin{array}{c}2,01- \\
3,00 \\
\mathrm{sm} \\
\end{array}$ & $\begin{array}{l}3,01- \\
4,00 \\
\mathrm{sm}\end{array}$ & $\begin{array}{c}4,01- \\
5,00 \\
\mathrm{sm} \\
\end{array}$ & $\begin{array}{c}5,01- \\
7,00 \\
\mathrm{sm} \\
\end{array}$ & $\begin{array}{c}7,01- \\
10,00 \\
\mathrm{sm} \\
\end{array}$ & $\begin{array}{c}10,01- \\
15,00 \\
\mathrm{sm}\end{array}$ & $\begin{array}{c}15,01- \\
20,00 \\
\mathrm{sm}\end{array}$ & $\begin{array}{c}\geq 20,00 \\
\text { sm }\end{array}$ & Ignorado \\
\hline 1999 & 2.435 & 44.234 & 162.492 & 307.416 & 382.518 & 198.418 & 111.511 & 138.405 & 91.730 & 63.960 & 28.400 & & 7.455 \\
\hline 2000 & 2.324 & 44.106 & 187.204 & 345.441 & 395.927 & 199.917 & 112.530 & 138.746 & 87.517 & 61.750 & 28.144 & & 9.050 \\
\hline 2002 & 4.011 & 62.322 & 338.636 & 394.424 & 411.277 & 184.404 & 114.943 & 117.449 & 77.692 & 50.086 & 22.680 & & 4.096 \\
\hline 2004 & 4.840 & 67.308 & 414.757 & 463.548 & 458.285 & 195.228 & 122.071 & 120.269 & 76.788 & 52.088 & 23.313 & & 5.814 \\
\hline 2006 & 6.095 & 72.831 & 670.477 & 464.269 & 441.058 & 194.715 & 114.364 & 110.191 & 68.697 & 45.138 & 20.883 & & 19.703 \\
\hline 2008 & 7.399 & 83.799 & 781.895 & 516.871 & 478.573 & 205.721 & 118.443 & 117.159 & 73.676 & 45.328 & 21.187 & & 31.100 \\
\hline 2010 & .287 & 96.865 & 870.637 & 601.255 & 530.747 & 221.993 & 124.714 & 121.105 & 75.690 & 47.448 & 20.320 & 21.953 & 41.701 \\
\hline
\end{tabular}

Fonte: IPARDES (2012).

Podemos notar que o número de pessoas com concentração de renda alta (a partir de sete salários mínimos) tem reduzido, ao passo que o número de pessoas que recebem acima de 1,01 salários mínimos, aumentou ligeiramente (chegando a quase 1 milhão de pessoas em 2010). Houve também aumento de $95 \%$ na população com salário acima de 1,51 salários mínimos. Em relação à população em extrema pobreza, houve tendência de queda, comparada à região sul e também ao índice nacional [ainda que a frequência de pessoas com baixo rendimento aumente (a coluna "menor ou igual meio salário mínimo"), ela deve ser contrastada e comparada com o aumento geral da 
população, o que em número gerais garante o seu decréscimo]. Em 2009 o Paraná apresentou uma proporção de 2,3\% da população em extrema pobreza, comparado com 7,1\% em 2001 no mesmo estado (INSTITUTO DE PESQUISA ECONÔMICA APLICADA, 2012, p. 16).

\section{SAÚDE E SANEAMENTO}

É inegável a importância do saneamento básico para garantir a saúde de uma dada população. De tal forma, a dificuldade de acesso a estes recursos causa problemas generalizados de saúde e riscos à saúde pública (PENA; ABICALIL, 1999, p. 111). A falta de saneamento (que abrange a distribuição de água encanada, tratamento de esgoto, coleta de lixo e tratamento de resíduos sólidos), torna a população sujeita às diversas enfermidades, causando, por conseguinte, um maior impacto na mortalidade infantil (MENDONÇA; MOTTA, 2007, p. 15).

No contexto do desenvolvimento, é clara a relação entre maior acesso aos recursos de saneamento, redução da mortalidade infantil e melhora na qualidade de vida (fatores físicos, mentais e sociais) (HELLER, 1998, p. 77). Para o indicador de mortalidade infantil, seguem os seguintes dados:

Tabela 8 - Mortalidade infantil no Paraná nos anos de 1994, 2000 e 2010.

\begin{tabular}{cc}
\hline Ano & $\begin{array}{c}\text { Mortalidade Infantil } \\
\text { Coeficiente (mil nascidos vivos) }\end{array}$ \\
\hline 1994 & 25,13 \\
2000 & 19,55 \\
2010 & 12,1 \\
\hline
\end{tabular}

Fonte: IPARDES (2012).

Observa-se uma redução expressiva nos coeficientes de mortalidade infantil neste intervalo de 16 anos. Ainda que a Organização Mundial da saúde proponha como aceitável um coeficiente de 10 mortes a cada mil nascimentos, pode-se notar que os indicadores caminham para esta taxa de padrão internacional. Comparado ao cenário nacional, que no ano de 2007 ainda apresentou um coeficiente de 20 mortes a cada mil nascimentos, o Estado do Paraná apresenta um indicador satisfatório (INSTITUTO DE PESQUISA ECONÔMICA APLICADA, 2012, p. 19). 
0 acesso a recursos de saneamento nos domicílios também é um fator de desenvolvimento social. No Estado, dados de 2009 apresentam que é garantido o acesso de água encanada a 87,7\% da população. Ainda em relação ao Paraná:

No Paraná, acessos adequados a abastecimento de água estão além das médias nacional e sulista, ao longo de todo o período. Cerca de $2,8 \%$ de sua população viviam sem esse atendimento em 2009. Na zona rural, o percentual de cobertura era de 92,6\% naquele ano (INSTITUTO DE PESQUISA ECONÔMICA APLICADA, 2012, p. 29).

Pode-se então considerar, a partir dos dados apresentados, que houve melhorias significativas das condições essenciais à vida e ao desenvolvimento humano, tanto em índices nacionais quanto Estaduais, a exemplo do Paraná. Neste sentido, buscou-se salientar as melhorias, em termos de desenvolvimento econômico e social, demonstrando os avanços e evolução nos índices de educação, emprego e renda, saúde e saneamento.

\section{CONSIDERAÇÕES FINAIS}

Este trabalho buscou apresentar, em linhas gerais, um retrospecto da economia brasileira até os dias presentes, demonstrando uma melhora significativa nos indicadores que compõem os índices de desenvolvimento social. Cabe salientar que a descrição dos indicadores apresentados não é capaz de expressar a gama de indicadores para a análise em conjuntura da economia brasileira, porém busca orientar e demonstrar como alguns aspectos da realidade social, aferidos pelos indicadores, podem ser mensurados e disponibilizados para a população. Neste sentido, e ainda que de forma breve, pretendeu-se discorrer a respeito das articulações político-econômicas frente a crises internas e internacionais, que puderam estabelecer, somente após várias décadas, um ritmo de crescimento econômico visando a equidade social.

Ainda assim, frente a inúmeras melhorias e políticas criadas, visando garantir de forma concreta o novo desenvolvimentismo, é apropriado esclarecer que o país ainda apresenta deficiências estruturais (baixo nível de escolaridade, capacitação técnica, infraestrutura, burocracias, má gestão dos gastos públicos, corrupção) que impedem que o desenvolvimento brasileiro prossiga a índices positivos e de forma ininterrupta. Somente a partir da consolidação de boas políticas e contínuos esforços rumo a uma economia sólida, somada ao empenho em solucionar estes problemas estruturais é que poderemos almejar indicadores sociais e econômicos que garantem uma conjuntura sociopolítica mais estável e com mais justiça social. 


\section{REFERÊNCIAS}

BALTAR, Ronaldo; BALTAR, Claudia Siqueira. A defasagem das ciências sociais no uso de recursos de informática para o ensino e a pesquisa no Brasil. La Educación - Revista Digital (OEA), Washington, v. 144, 2010.

BONELLI, Regis. 0 que causou o crescimento econômico no Brasil. In: GIAMBIAGI, F. et al. (Org.). Economia brasileira contemporânea (1945-2004). Rio de Janeiro: Campus, 2005.

BRASIL. Decreto $n^{0}$ 6.094, de 24 de abril de 2007. Dispõe sobre a implementação do Plano de Metas Compromisso Todos pela Educação, pela União Federal, em regime de colaboração com Municípios, Distrito Federal e Estados, e a participação das famílias e da comunidade, mediante programas e ações de assistência técnica e financeira, visando a mobilização social pela melhoria da qualidade da educação básica. Brasília, 2007.

BRASIL. Ministério da Educação. Instituto Nacional de Estudos e Pesquisas Educacionais. Mapa do analfabetismo no Brasil. Brasília, DF: MEC/ INEP, 2003.

PEREIRA, Luiz Carlos Bresser. 0 novo desenvolvimentismo e a ortodoxia convencional. São Paulo em Perspectiva, São Paulo, v. 20, n. 3, p. 5-24, jul./set. 2006.

DELFIM NETTO, Antonio. Meio século de economia brasileira: desenvolvimento e restrição externa. . In: GIAMBIAGI, F. et al. (0rg.). Economia brasileira contemporânea (1945-2004). Rio de Janeiro: Campus, 2005.

DELGADO, Paulo Roberto; BESEN, Gracia Maria V. In: INSTITUTO PARANAENSE DE DESENVOLVIMENTO ECONÔMICO E SOCIAL - IPARDES. Índice IPARDES de desempenho municipal: evolução do componente renda e emprego. Curitiba: IPARDES, 2009. Nota Técnica

DWYER, Thomas Patrick. Sociologia e tecnologias de informação e comunicação. In: BRASIL. Ministério da Educação. Sociologia: ensino médio. Brasília: MEC, 2010. Explorando o Ensino, Cap. 8, v. 15.

FAUSTO, Bóris. História concisa do Brasil. 2. ed. São Paulo: Edusp, 2012.

HELLER, Leo. Relação entre saúde e saneamento na perspectiva do desenvolvimento. Ciência \& Saúde Coletiva, Rio de Janeiro, v. 3, n. 2, p. 73-84, 1998.

INSTITUTO DE PESQUISA ECONÔMICA APLICADA - IPEA. Situação social nos estados: Paraná. Brasília: IPEA, 2012.

INSTITUTO PARANAENSE DE DESENVOLVIMENTO ECONÔMICO E SOCIAL - IPARDES. Leituras regionais: mesorregiões geográficas paranaenses. Curitiba: Ipardes: BRDE: 2004. 
INSTITUTO PARANAENSE DE DESENVOLVIMENTO ECONÔMICO E SOCIAL - IPARDES. Caderno estatístico do Estado do Paraná. Curitiba, 2012.

LEVIN, Jack; FOX, James Alan. Estatística para ciências humanas. 9. ed. São Paulo: Pearson Prentice Hall, 2004.

MATTEI, Lauro. Gênese e agenda do novo desenvolvimentismo brasileiro. In: ENCONTRO BRASILEIR0 DA AKB, 4., 2011, Rio de Janeiro. Anais... Rio de Janeiro: AKB, 2011.

MENDONÇA, Mário Jorge Cardoso; MOTTA, Ronaldo Seroa. Saúde e saneamento no Brasil. Planejamento e Políticas Públicas, Brasília, v. 30, jun./dez. 2007.

MORAES NETO, José. 0 emprego e as políticas governamentais. Mercado de Trabalho, Brasília, v. 10, n. 27, p. 3-6, maio, 2005.

OLIVEIRA, Carlos Alonso Barbosa. Quinze anos depois: comentários sobre o texto "Paraná - Economia e Sociedade". Revista Paraense de Desenvolvimento, Curitiba, n. 83, set./dez. 1994.

PAIVA, Carlos Águedo Nagel. Noções de economia. Brasília: Fundação Alexandre de Gusmão, 2008.

PENA, Dilma; ABICALIL, Marcos Thadeu. Saneamento: os desafios do setor e a política nacional de saneamento. In: INSTITUTO DE PESQUISA ECONÔMICA APLICADA. Infraestrutura: perspectivas de reorganização, saneamento. Brasília: IPEA, 1999. p. 107137.

REDE INTERAGENCIAL DE INFORMAÇÃO PARA A SAÚDE - RIPSA. Indicadores básicos para a saúde no Brasil: conceitos e aplicações. 2. ed. Brasília: Organização PanAmericana da Saúde, 2008.

SOUZA, Marcelo Medeiros Coelho. 0 analfabetismo no Brasil sob enfoque demográfico. Cadernos de Pesquisa, São Paulo, n. 107, jul. 1999. Disponível em: $<$ http://educa.fcc.org.br/scielo.php?script=sci_arttext\&pid=S0100>. Acesso em: 15 jan. 2012.

TRINTIN, Jaime Graciano. A economia Paranaense: 1985-1998. 2001. 187 f. Tese (Doutorado em Economia) - Instituto de Economia, UNICAMP, Campinas, 2001.

TRINTIN, Jaime Graciano. História e desenvolvimento da economia paranaense: da década de trinta a meados da década de noventa do século XX. In: SEGUNDAS JORNADAS DE HISTÓRIA REGIONAL COMPARADAS, 2005, Porto Alegre. Anais... Porto Alegre: Fundação de Economia e Estatística, 2005. 